\title{
Heat recovery from Combined Cycle Power Plants for Heat Pumps
}

\author{
Alberto Vannoni ${ }^{1}$, Alessandro Sorce ${ }^{1}$, Sven Bosser ${ }^{2, ~}{ }^{*}$, and Torsten Buddenberg ${ }^{2, *}$ \\ ${ }^{1}$ Thermochemical Power Group, University of Genoa, Viale Cambiaso 4, 16145 Genova, Italy \\ ${ }^{2}$ Mitsubishi Hitachi Power Systems Europe GmbH, Schifferstr. 80, 47059 Duisburg, Germany
}

\begin{abstract}
Fossil fuel power plants, as combined cycle plants (CCGT), will increasingly have to shift their role from providing base-load power to providing fluctuating back-up power to control and stabilize the grid, but they also have to be able to run at the highest possible efficiency. Combined Heat and Power generation could be a smart solution to overcome the flexibility required to a modern power plant, this work investigates different layout possibilities allowing to increase the overall efficiency through the heat recover from the hot flue gasses after the heat recovery steam generator (HRSG) of a CCGT. The flue gas (FG) cooling aims to recover not only the sensible heat but also the latent heat by condensing the water content. One possible solution couples a heat pump to the flue gas condenser in order to increase the temperature at which the recovered heat is supplied, moreover the evaluated layout has to comply with the requirement of a minimum temperature before entering the stack.
\end{abstract}

\section{Introduction}

Nowadays power and heat production sectors must deal with the energy transition scenario according to the goal of progressive decarbonization of society, research is focused on reducing the primary energy demand and big fossil power plants are required to be at the same time more and more efficient and flexible. Among fossil fuel-based technology CCGT power plants operating in combined heat and power (CHP) mode are considered as the most efficient solution to exploit the fuel energetic potential. Moreover, the possibility of varying the ratio between the power and the heat produced makes this type of plant promising solution with respect to flexibility requirements, allowing to produce more heat when the price of energy is too low to be profitable. As thermal user, the Turin District Heating Network (DHN) was selected: a second generation DHN with an upper temperature of $120^{\circ} \mathrm{C}$ and a return of $70{ }^{\circ} \mathrm{C}$.

With respect to a standard Heat Recovery Steam Generator (HRSG), a further exploitation of the flue gasses could be implemented recovering not only the sensible heat but also the latent heat of water vapor contained in the flue gasses [1,2]. Such flue gas cooler can be designed as indirect heat exchanger or as spray cooler derived from a flue gas scrubber.

\footnotetext{
* Corresponding authors: $\underline{\text { s_bosser@eu.mhps.com and t buddenberg@eu.mhps.com }}$
} 
The heat recovered by flue gasses increases linearly within a decrement of the temperature at the stack until the dew point at which, for further decrements of temperature, condensation occurs. The heat recovered by condensation first increases very quickly for temperatures slightly below the dew point, then more and more slowly since the slope of saturation curve on the psychometrics diagram is greater for high temperatures [3]. Condensing the flue gas to recover the latent heat requires, of course, to cool them below the dew point temperature, approximately $50-55^{\circ} \mathrm{C}$ depending on excess air ratio. In any case the flue gas must have a minimum temperature before it enters the stack in order to guarantee a sufficient buoyancy effect to increase pollutant dispersion, in this work a minimum temperature of $60{ }^{\circ} \mathrm{C}$ and $50{ }^{\circ} \mathrm{C}$ were chosen. Consequently, any layout configuration should reheat the flue gases after the exploitation of latent heat in order to satisfy the minimum temperature requirement at the stack. Any layout considering a direct regenerative heat exchange between the gas before and after the condenser implies huge gas/gas surface area heat exchangers thus high cost. So is supposed a case (Case 1, schematized in Fig.2) in which FG are heated to $60{ }^{\circ} \mathrm{C}$ exploiting the water coming from the $\mathrm{DHN}$ with a temperature of $70{ }^{\circ} \mathrm{C}$. The water, cooled by the exhaust gases, is then heated again, by the gases approaching the condenser, more or less up to $70{ }^{\circ} \mathrm{C}$, small differences occur because of slight variations in the mass flow and specific heat of the FG through the condensation.

Since the latent heat can be recovered only at temperatures lower than the dew point, that are not high enough for the most of possible applications, a coupling with a heat pump (HP), in order to upgrade the temperature at which this heat is available, is needed. Some possible solutions to couple HPs and CHP-CCs have been already investigated by Ommen [4], even if without considering the possibility of latent heat recovery. For these reasons, three configurations are proposed to recover energy from the flue gases:

Table 1. Cases summary

\begin{tabular}{|c|c|c|c|}
\hline Case \# & Flue gas cooler & Flue gas Reheat & HP type \\
\hline Case1.Series & $\begin{array}{c}\text { indirect heat } \\
\text { exchanger }\end{array}$ & Indirect & $\begin{array}{c}\text { Warm temperature, installed in series, for } \\
\text { DHN water production }\left(16 \text { bar, } 120^{\circ} \mathrm{C}\right)\end{array}$ \\
\hline Case1.Parallel & $\begin{array}{c}\text { indirect heat } \\
\text { exchanger }\end{array}$ & Indirect & $\begin{array}{c}\text { Warm temperature, installed in parallel for } \\
\text { DHN water production }\left(16 \text { bar, } 120^{\circ} \mathrm{C}\right)\end{array}$ \\
\hline Case2.Direct & spray tower & Regenerator & $\begin{array}{c}\text { High Temperature for Steam production } \\
\left(4.2 \text { bar, } 160^{\circ} \mathrm{C}\right)\end{array}$ \\
\hline
\end{tabular}

In layout 1, all the heat exchange with the flue gases occurs in an HRSG arrangement: the same geometry of conventional finned tube heat exchanger is adopted in order to introduce flue gas energy recovery additional equipment. Moreover, some constraints were introduced in order to limit flue gas condensation (and so possible acid depositions) to the HP evaporator reducing the material quality requirements for the other heat exchangers. Two subcases are analysed to quantify the effect of the arrangement of the HP with respect to the main DHN heat exchanger (DHN-HX).

One of the most important parameters on which the value of the investigated configurations is evaluated is the global efficiency, defined as the ratio of the overall net power on the product of fuel mass flow and its lower heat value (LHV). Then, recovering the latent heat from flue gasses, efficiencies of more than $100 \%$ are theoretically achievable. 


\section{Possible layout configurations}

\subsection{Case 1}

The present case takes into account a $400 \mathrm{MW}$ gas turbine combined cycle working in CHP mode with a district heating network (DHN) to which the water is supplied at $120{ }^{\circ} \mathrm{C}$ and comes back at $70{ }^{\circ} \mathrm{C}$. Gas turbine is a series $\mathrm{F}$ turbine whose exhaust gas and mass flow and temperatures vary with the load according to the Table $2,45 \%$ is the minimum environmental load. Lowering the load below $75 \%$ the temperature of exhaust gasses remains constant since the fuel air ratio is constant.

Table 2. Temperatures and exhaust mass flow values at different gas turbine loads [5].

\begin{tabular}{|c|c|c|c|c|}
\hline GT Load [\%] & 100 & 75 & 60 & 45 \\
\hline Mass flow [kg/s] & 666 & 565 & 505 & 444 \\
\hline Temperature [ $\left.{ }^{\circ} \mathrm{C}\right]$ & 573 & 558 & 558 & 558 \\
\hline
\end{tabular}

The bottoming cycle is supposed to be the industrial standard three pressure level with reheat system. The heat recovered by the feedwater can be more than what is required by the steam cycle, so the excess flow heated up to $120^{\circ} \mathrm{C}$ could be used to supply heat directly to the DHN. This additional recovery could be performed by a separate heat exchanger, working in parallel to the standard feed-water heater (FWH). Anyhow, the main way to increase the thermal power production is to extract some steam from the lowpressure (LP) turbine inlet and condense it delivering heat to the water going to the DHN. In this way, on one hand the heat available to the DHN increases, on the other hand the mass flow through the LP turbine decreases and the global power production as well, while the global efficiency increases. With reference to Fig.1, keeping the load constant, the steam extraction results in a shift on the right side of the diagram with a rising of global efficiency.

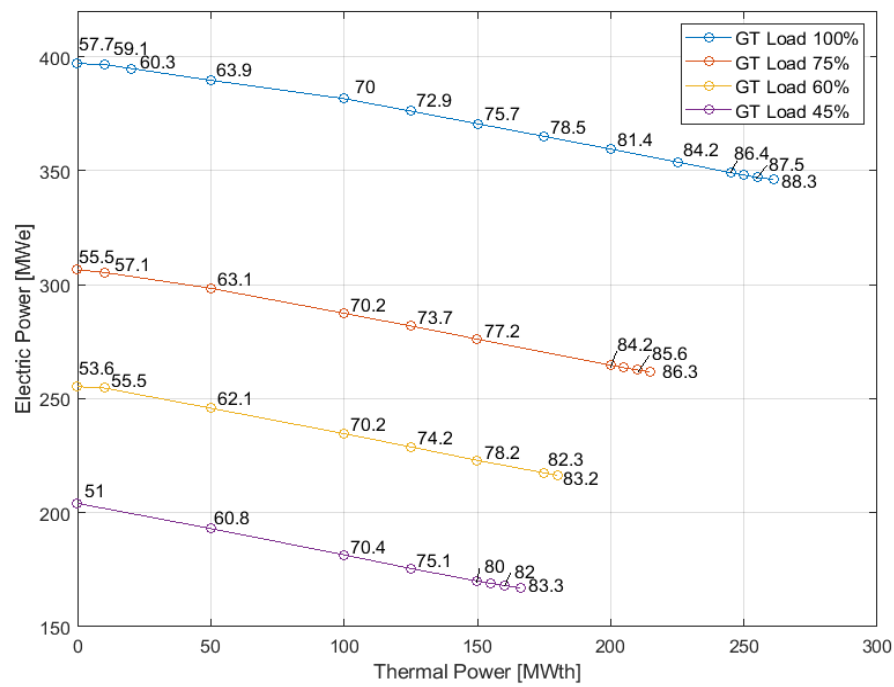

Fig. 1. Iron Diagram of standard layout recovering only the FG sensible heat. Labels show the global efficiency

So, three sources of heat are considered: the high temperature heat recovery directly from the FG sensible heat, in parallel with the bottoming cycle feedwater heater, the main DHN exchanger, exchanging heat with the steam extracted from the LP steam turbine, and finally the latent heat from the flue gases condensation, upgraded by the HP. So, there are 
many possibilities to connect these three components and the water circuit able to guarantee $60{ }^{\circ} \mathrm{C}$ at the stack. In order to limit the number of layouts examined in this preliminary analysis some constraints are imposed: The high temperature heat recovery, and the DHN$\mathrm{HX}$ has to be linked in parallel, suppling water at $120^{\circ} \mathrm{C}$ directly to the DHN, having similar temperature to the hot side. The heat pump must be linked in series with the reheating water, this allows to have no limits on the minimum temperature level at the flue gasses condenser exit otherwise there is a minimum temperature below which the water mass flow is not enough to reheat the gasses up to $60^{\circ} \mathrm{C}$. Finally, to perform the FG reheat before the stack, the DHN return, due to the matching temperature, was deployed. Taking into account all this constraints two main layouts are defined (HP-Parallel and HP-Series) and sketched in Fig. 2, some variants to the layout HP-Series are possible and could be object of future investigations.

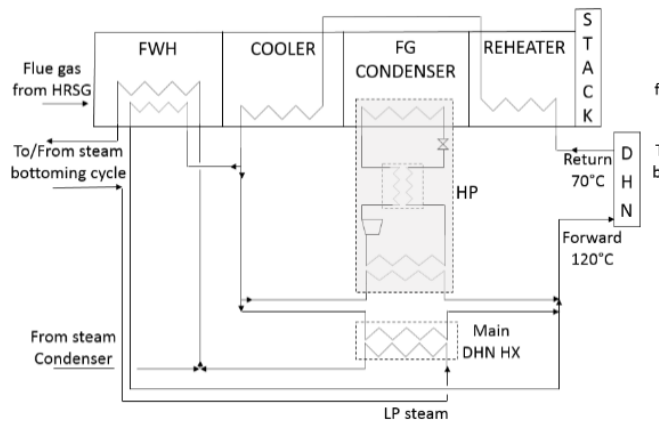

(a)

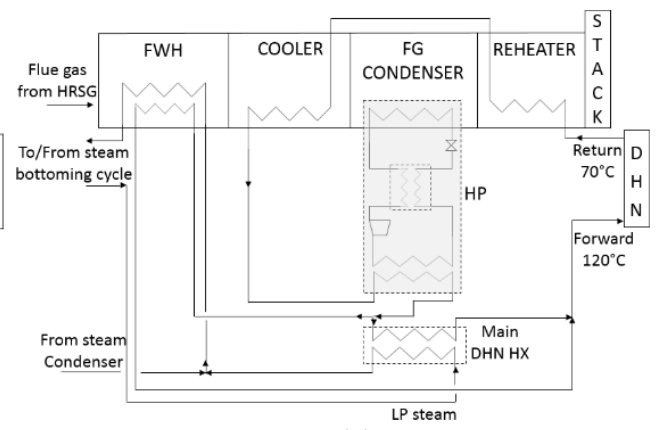

(b)

Fig. 2. The two investigated configurations of Case 1: (a) HP-Parallel, (b) HP-Series

\subsection{Case 2}

The approach of this layout option is to recover heat from the hot flue gases after the HRSG with the purpose of production of additional steam with the HP. The flue gas condenser can be designed as spray cooler, where the condensate is removed in the swamp and the circulation pump transports it to the HP. In any case the flue gas must have a minimum temperature of $50{ }^{\circ} \mathrm{C}$ before it enters the stack, and this is done by the regenerator.

The reference power plant model for the investigation of the performance of the Case 2 layout option is based on an industrial CC power plant for cogeneration of electricity, process steam and hot water. The combined cycle is a 1-1-1 configuration (1 gas turbine on 1 HRSG on 1 steam turbine). Behind the back-pressure steam turbine, $201.6 \mathrm{MW}_{\text {th }}$ of process steam at a pressure of 4.2 bar and a temperature of $160{ }^{\circ} \mathrm{C}$ are extracted for the local industrial steam grid. In the steam condenser water is heated up to $145^{\circ} \mathrm{C}$ (hot factory feed water, FFW). The 2 separated return flows of factory feed water to the CHP plant have a temperature of $75{ }^{\circ} \mathrm{C}$ (Warm) and $20^{\circ} \mathrm{C}$ (Cold). Before the steam turbine, external steam from the local steam grid (Hot Ring) is introduced into the CHP cycle to increase the electrical power generation and the production of process steam at a pressure of 4.2 bar. The electricity production is $40.7 \mathrm{MW}_{\mathrm{el}}$ by the generator of the gas turbine and $26.3 \mathrm{MW}_{\mathrm{el}}$ by the steam turbine generator. Considering the consumption of all auxiliary equipment, the total net electricity production is $65.7 \mathrm{MW}_{\mathrm{el}}$. 


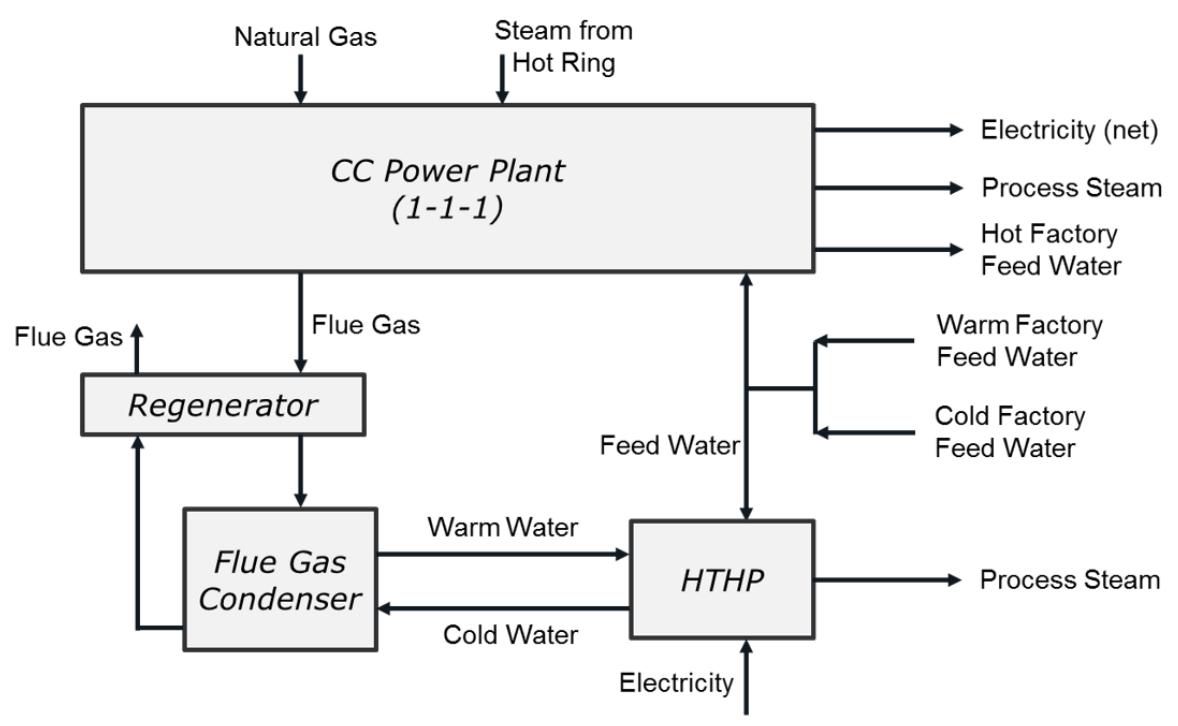

Fig. 3. The investigated configuration of Case 2

\section{Mathematical models}

In order to investigate the limits and potentialities of the two layouts of Case1, a MATLAB model was developed for the heat exchangers, the condensing process and the heat pump. For the rest of the combined cycle, data already available obtained via GateCycle has been used [5].

For the condensing process the model has been developed basing on the Psicometicsnew[6] function but instead of using the dry air specific heat, as well in [3], a proper value of dry FG specific heat is computed knowing the composition of gasses. The heat exchangers were modelled exploiting energy balance equations and the terminal temperature difference approach, neglecting any kind of head loss in the flow. Temperatures and mass flow are iteratively calculated. Regarding the heat pump the whole thermodynamic cycle has been modelized using CoolProp database[7].

The modelized cycle is a classical HP vapor compression cycle with regeneration, the cycle is such as to maximize, with the given source and sink temperature, the COP within the respect of some constraints mainly related to minimum temperature differences required at the heat exchangers, on the other hand the mass flow of working fluid is set as the value that allows to take off from the sources the amount of heat given as an input. The table below summarizes the most important assumptions considered in modelling the heat pump.

Table 3. Assumption in HP modelling Case 1

\begin{tabular}{|c|c|c|c|c|c|}
\hline Fluid & $\Delta \mathrm{T}_{\mathrm{SH}}$ & $\eta_{\text {compressor }}$ & $\Delta \mathrm{T}_{\mathrm{EVA}}$ & $\Delta \mathrm{T}_{\mathrm{COND}}$ & $\Delta \mathrm{T}_{\text {regenerator }}$ \\
\hline $\mathrm{R} 600$ & $25^{\circ} \mathrm{C}$ & 0.64 & $3^{\circ} \mathrm{C}$ & $4^{\circ} \mathrm{C}$ & $3^{\circ} \mathrm{C}$ \\
\hline
\end{tabular}

To model the Case 2 layout a detailed model of the reference CHP plant is built with the commercial simulation software EBSILON $®$ Professional. This model allows an accurate investigation of the impact of the integration of the HP into the power plant cycle on the performance of this $\mathrm{CC}$ power plant. The HP model was also built with EBSILON®Professional and is integrated into the power plant model. 


\section{Analysis and results}

\subsection{Case 1}

The easiest way to understand when it is convenient to switch the heat pump on is to look at the Iron Diagram. If without any heat pump to match a specific demand both electric and thermal there was only a possible combination of GT load and steam extracted, with the heat pump the most of points on the Iron Diagram are reachable by several combination of the GT load, HP power and steam extraction. Anyway, before reaching the full extraction condition (red line in Fig. 4) is preferable keeping the HP switched off and varying the two other variables to match the demand requirements. This is why even if, in some partial extraction conditions, it would be theoretically more convenient to activate the HP rather of extract more steam, the advantages are too modest $(0.3 \%$ of power increment for the same thermal production) to justify such a complication of operating. The great advantage of the HP is rather the possibility to extend to higher thermal power the operating range, increasing the flexibility of the plant. So practically the best way to operate the plant is to run the HP only when the maximum flow of steam is extracted, increasing progressively the electric power to the compressor to deal with the thermal demand.

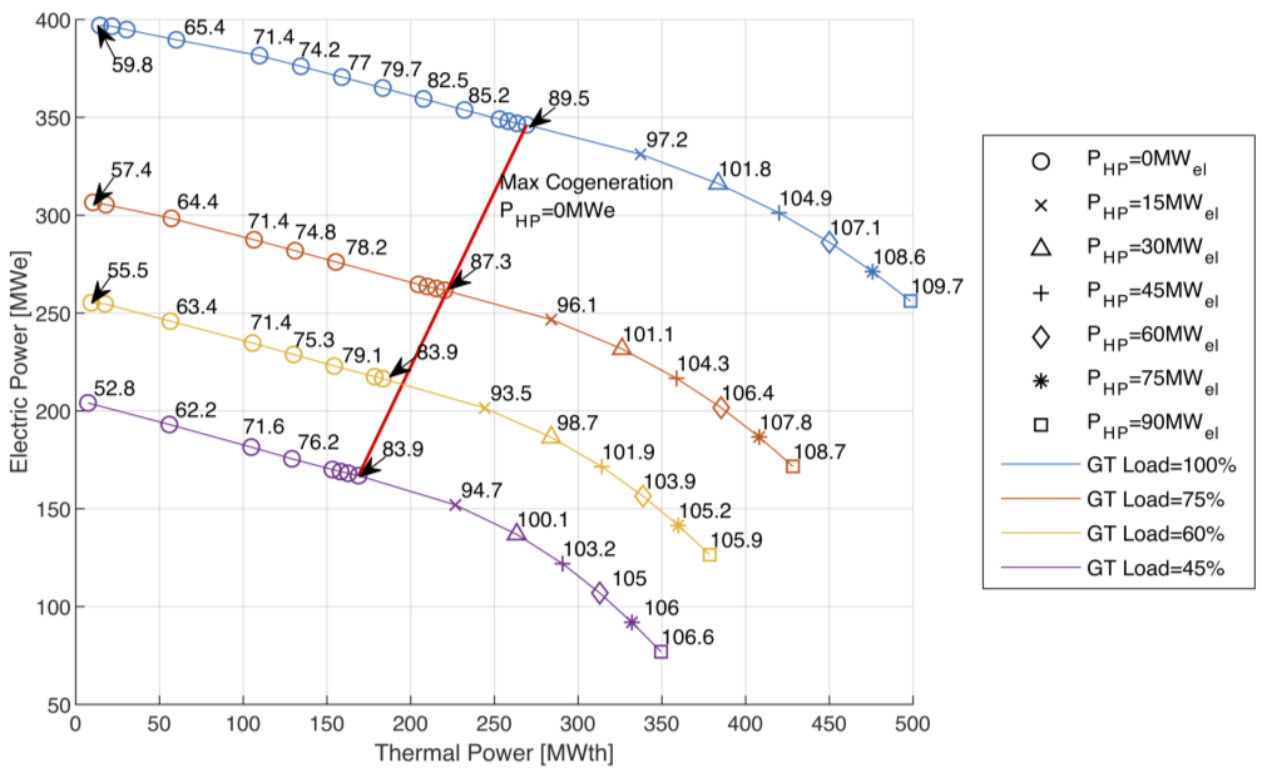

Fig. 4. Iron Diagram - CCGT with the HP-Series, is shown an extra region extending the operating conditions to higher thermal production levels in which the power of the heat pump is progressively increased. The difference between HP-Series and HP-Parallel is too small to be appreciate on this diagram, a comparison is reported in Fig.5b. Labels show the global efficiency

A further analysis has been performed to investigate how much of the exploitable latent heat in the flue gasses is used in each layout. GT load equal to $60 \%$ and maximum extraction condition are chosen since, as explained above, is a typical condition in which the use of HP could be profitable in case of low electrical price. Since in the HP-Series layout the water temperature at the HP-condenser exit is lower than $120{ }^{\circ} \mathrm{C}$, suppling the same electrical power to the HP-compressor, at the HP-evaporator the temperature is lower than in HP-Parallel configuration. Consequently, the flue gasses are cooled to a lower temperature and more latent heat is exploited than in Case1-Parallel, it could be appreciated by the Fig. 5 a. 


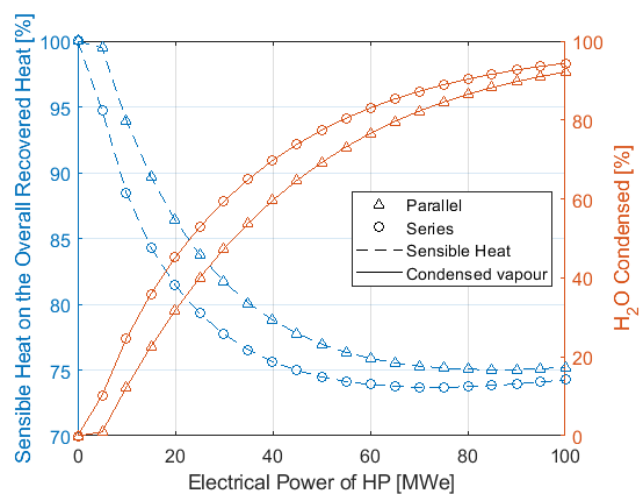

(a)

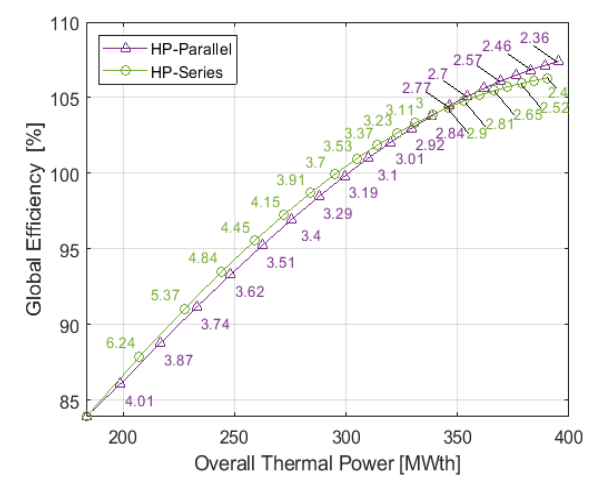

(b)

Fig. 5. Effectiveness of latent heat recovery and global efficiency trend versus the overall thermal production, labels show the HP COP.

In the same conditions is also investigated the trend of global efficiency and the HP $\mathrm{COP}$ in the two layout options considered. To an increment of HP electric power follows an increment of the overall thermal production, that is reported on the $\mathrm{x}$-axes of Fig.5b. In the HP-Series configuration the overall efficiency increases, and remains greater than the layout HP-Parallel, until the power of the heat pump is such that the outlet temperature is too high to allow an appropriate exploitation of heat in the two last exchangers. The COP mainly depends on the difference between the HP evaporator and the HP condenser, so it is always greater for the HP-Series case and progressively decreases increasing HP power. The following figure (Fig.6) explains this phenomenon: highlighting the ratio between the heat exploited in the DHN-HX on the heat here exploitable if the inlet, on the cold side, was the water coming from the $\mathrm{DHN}$ at $70^{\circ} \mathrm{C}$, as in the standard layout without any heat pumps. In the HP-Parallel layout this ratio is almost one, slightly higher because the temperature at the Cooler exit slightly differs from $70^{\circ} \mathrm{C}$ as explained in the first section. In the HP-Series case this parameter decreases as the HP power increases, since the DHN water is preheated by the heat pump, reducing the energy recovery in the DHN-HX, (up to $-3.5 \%$ for HP power equal to $50 \mathrm{MW}_{\mathrm{el}}$ ), this effect is particularly relevant at lower GT load. This is the reason why, for high thermal demand, the HP-Parallel layout presents a higher global efficiency despite the fact the COP of HP-Series installed heat pump is greater.

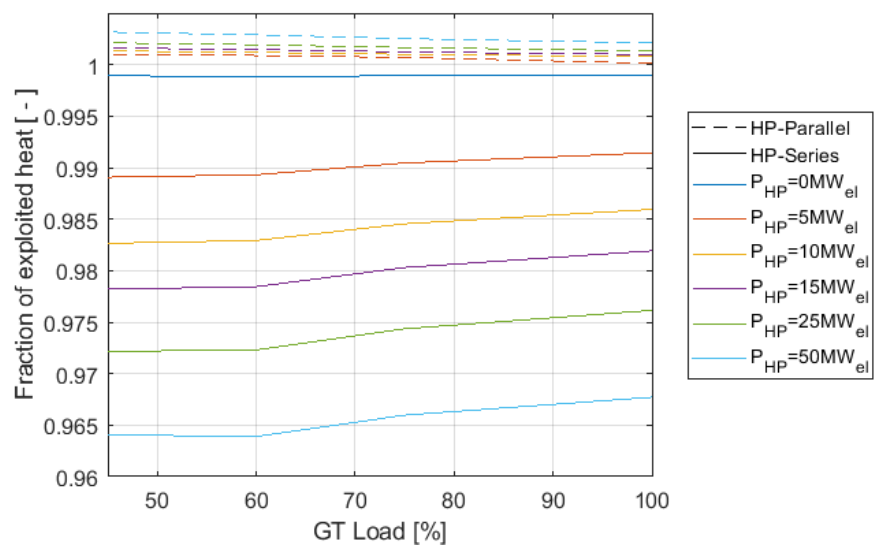

Fig. 6. Ratio between the heat recovered and the heat ideally recoverable in the DHN-HX for HP-Parallel and HP-Series layouts and different HP powers. 


\subsection{Case 2}

The reference $\mathrm{CC}$ power plant has a net fuel utilisation factor of $90.8 \%$. The net fuel utilisation factor considers all incoming and outgoing enthalpy fluxes (e.g. from the hot ring and the factory feed water) and the net electricity production divided by the fuel heat based on LHV. The power to heat ratio which is the ratio of net electricity production to net heat production (sum of all incoming and outgoing enthalpy fluxes $\dot{H}_{i}$ ) is 0.55 .

The following table (Table 4) summarises the results of the performance calculations of the CC reference power plant model (CHP Basis) and of the combination of the CC power plant with the HP, producing 54.3 $\mathrm{MW}_{\text {th }}$ of process steam at a pressure of 4.2 bar and a temperature of $160{ }^{\circ} \mathrm{C}$. The power to heat ratio is decreased which is logical because the HP uses electricity to produce additional heat. The table shows that the net fuel utilisation factor can be increased significantly, this is because waste heat from the flue gases is used which is usually not used in CHP power plants. At the same time the power to heat ratio is decreased significantly which is good if heat production is the main focus of the application. This layout option is only suitable for an industrial application with demand for process steam, because storing und using the produced heat in the power plant itself is not feasible. As this layout option is a promising approach to increase the net fuel utilisation factor of industrial CHP plants it will be object of the further investigations of the project with regards to the high temperature heat pump.

In the further studies of PUMP-HEAT project, the COP of the heat pump table should be increased by creating an optimised design of the HP process, taking into account the boundary conditions of this layout option which is mainly the different specification of the heat source.

Table 4. Case 2 results, values in MW except for efficiencies and COP

\begin{tabular}{|c|c|c|c|c|}
\hline System & & Parameter & CHP Basis & $\mathrm{HP}$ \\
\hline \multirow{6}{*}{$\mathrm{CC}$} & $\mathrm{P}_{\text {el netCC }}$ & OUT & $65.7 \mathrm{MW}$ & $56.6 \mathrm{MW}$ \\
\hline & \multirow{4}{*}{$\mathrm{Q}_{\mathrm{iCC}}$} & Hot Ring IN & $-82.9 \mathrm{MW}$ & $-24.6 \mathrm{MW}$ \\
\hline & & Process Steam OUT & $201.6 \mathrm{MW}$ & $153.7 \mathrm{MW}$ \\
\hline & & Return Water IN & $-21.4 \mathrm{MW}$ & $-21.2 \mathrm{MW}$ \\
\hline & & Hot FFW OUT & $21.2 \mathrm{MW}$ & $21.2 \mathrm{MW}$ \\
\hline & $\mathrm{m}_{\mathrm{B}} * \mathrm{LHV}$ & IN & $202.8 \mathrm{MW}$ & $202.8 \mathrm{MW}$ \\
\hline \multirow{3}{*}{ HP } & $\mathrm{P}_{\text {el_net_HTHP }}$ & IN & $0.0 \mathrm{MW}$ & $-28.3 \mathrm{MW}$ \\
\hline & & Return FFW IN & $0.0 \mathrm{MW}$ & $-5.0 \mathrm{MW}$ \\
\hline & & Process Steam OUT & $0.0 \mathrm{MW}$ & $54.3 \mathrm{MW}$ \\
\hline \multicolumn{3}{|c|}{ Net Fuel Utilisation Factor } & $90.8 \%$ & $101.9 \%$ \\
\hline \multicolumn{3}{|c|}{ Power to Heat ratio } & 0.55 & 0.16 \\
\hline \multicolumn{3}{|c|}{ Net Electric efficiency } & $32.4 \%$ & $27.9 \%$ \\
\hline \multicolumn{3}{|c|}{ COP of HP } & 0.0 & 1.74 \\
\hline
\end{tabular}

\section{Conclusion}

Flue gasses condensing in a CCGT power plants demonstrate to be a suitable technology to further exploit the potential of the fuel allowing to reach, for all the investigated layouts, global efficiency vales well above $100 \%$ and the HP permits to low the power to heat ratio giving extra flexibility. Therefore, coupling these two technologies demonstrate to be promising for modern power plants.

The study of Case1 options shows that the HP-Series case, where the return water from the DHN is preheated by the HP before entering the DHN-HX, is preferable since the HP 
works with better COP. Nevertheless, in high heat demand conditions when high HP power are needed the temperature entering the DHN-HX is too high to exploit all the heat potential of the extracted steam and the HP-Parallel configuration becomes advantageous.

Comparing the Case 1 and the Case 2, looking at the Fig. 3 and the Table 4, appears that, working the $\mathrm{HP}$ at $30 \mathrm{MW}_{\mathrm{el}}$, the two options have similar values in global efficiency, but has to be taken into account that in the Case 2 the flue gasses are exploited until $50{ }^{\circ} \mathrm{C}$ instead of $60{ }^{\circ} \mathrm{C}$. So, Case 1 layout seems to perform better, probably because of the higher $\mathrm{COP}$ due to the higher temperature at which the steam is produced.

\section{Acknowledgments}

This project has received funding from the European Union's Horizon 2020 research and innovation programme under Grant Agreement No 764706, PUMP-HEAT. (http://www.pumpheat.eu).

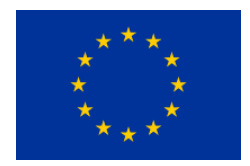

\section{References}

[1] Babcock \& Wilcox Vølund AB, Flue gas condensation, http://www.gmab.se/fluegas-condensation

[2] Albul, Andrei et al., Combined cycle gas turbine efficiency enhancement using heat pumps for thermal power plants, The International Gas Union Research Conference 2014 Proceedings, Copenhagen, Denmark.

[3] American Society of Heating, Refrigerating and Air-Conditioning Engineers. (2009). 2009 ASHRAE handbook: Fundamentals. Atlanta, GA: American Society of Heating, Refrigeration and Air-Conditioning Engineers.

[4] Ommen, T., Markussen, W.B., Elmegaard, B., Heat pumps in combined heat and power systems (2014) Energy, 76, pp. 989-1000.

[5] Sorce, A., Giugno, A., Marino, D., Piola, S., and Guedez, R., 2019, “Analysis Of A Combined Cycle Exploiting Inlet Conditioning Technologies For Power Modulation," Proceedings of ASME Turbo Expo 2019: Turbomachinery Technical Conference and Exposition GT2019.

[6] https://it.mathworks.com/matlabcentral/fileexchange/49154-si-psychrometric-chart

[7] I.H. Bell, J. Wronski, S. Quoilin, V. Lemort, Pure and pseudo-pure fluid thermophysical property evaluation and the open-sourcethermophysical property library CoolProp, Ind. Eng. Chem. Res. 53 (2014) 2498-2508, https://doi.org/10.1021/ie4033999. 